\title{
Sacred natural sites and biodiversity conservation: a systematic review
}

\author{
Piero Zannini ${ }^{1}$ (D) . Fabrizio Frascaroli ${ }^{1,2}$. Juri Nascimbene ${ }^{1}$ (D) Angela Persico ${ }^{1}$. \\ John Maxwell Halley ${ }^{3}$. Kalliopi Stara ${ }^{3}$ (D) . Gabriele Midolo ${ }^{4}$ (D) . \\ Alessandro Chiarucci ${ }^{1}$ (D)
}

Received: 29 May 2021 / Revised: 4 September 2021 / Accepted: 15 September 2021 /

Published online: 30 September 2021

(C) The Author(s) 2021

\begin{abstract}
Sacred natural sites (SNS) have gained recognition from conservationists, and are regarded as the oldest form of habitat protection in human history. Many case studies and literature reviews have been published on the subject. However, an updated and global-level synthesis on the effect of SNS on biodiversity conservation is still lacking. Here, we provide the first systematic review on SNS and biodiversity conservation, aiming to evaluate the effect of SNS across different: (i) continents; (ii) taxa; (iii) metrics. We checked 2750 papers and by applying inclusion criteria we selected 27 relevant papers. From these, we extracted descriptive data and 131 comparisons between SNS and Reference Sites. We applied votecounting, multinomial and binomial post-hoc tests to the 131 comparisons. We found strong evidence that SNS have a positive effect on biodiversity, but also strong geographical and taxonomical biases, with most research focusing on Asia and Africa and on plants. We found that SNS have mainly positive effects on taxonomical diversity, vegetation structure and cultural uses of biodiversity. Our results strongly support the view that SNS have positive effects on biodiversity across continents and geographical settings, as found in a number of local studies and earlier overviews. These effects should be given official recognition in appropriate conservation frameworks, together with the specific forms of governance and management that characterize SNS. At the same time, further efforts are also required to fill the geographical and taxonomical gaps here highlighted, and to advancing our knowledge of SNS through more systematic research.
\end{abstract}

Keywords Biological conservation $\cdot$ Conservation biology $\cdot$ OECMs $\cdot$ Cultural landscapes $\cdot$ Protected areas $\cdot$ Vote-counting

Communicated by Daniel Sanchez Mata.

Piero Zannini and Fabrizio Frascaroli have contributed equally.

Juri Nascimbene

juri.nascimbene@unibo.it

Extended author information available on the last page of the article 


\section{Introduction}

The accelerated rate at which biodiversity is being eroded (Díaz 2019) is moving scientists to call for the conservation of large portions of the Earth (e.g., Locke 2013; Wilson 2016; Baillie and Zhang 2018; Dinerstein et al. 2020). While Protected Areas (PA) are regarded as the cornerstone of nature conservation, concerns are being raised about their capacity to halt effectively the current biodiversity crisis (Laurance et al. 2012; Watson et al. 2014). Interest has thus been increasing in complementary conservation measures, which may integrate and possibly overcome some of the limitations of PA. One such type of measures has been defined and legally ratified by the International Union for Conservation of Nature and the Convention on Biological Diversity as Other Effective Area-Based Conservation Measures (OECMs). These include a broad range of cases, from private estates to ancestral lands, in which conservation is not the primary purpose of land management, as in the case of PA, but consistently delivered as a by-product of other management goals (IUCN WCPA 2019).

SNS are another example of nature protection independent of PA, despite being often spatially overlapping with PA, which has received considerable recognition from conservationists over the last two decades. SNS have been defined as "areas of land or water having special spiritual significance for peoples and communities" (Wild \& McLeod 2008). SNS are associated to a wide range of natural features, such as single trees or rock outcrops, rivers, mountains, islands and even entire landscapes (Dudley et al. 2005), although it seems that the majority are sacred groves and forest patches (Dudley et al. 2010). Sometimes, SNS can also consist of built features, such as temples, shrines or monasteries, surrounded by natural or semi-natural areas (Dudley et al. 2009; Frascaroli et al. 2016a,b).

From a conservation perspective, SNS are often regarded as the oldest form of conservation of habitats and other types of natural resources in human history (Dudley et al. 2005), in some cases having existed for many centuries or even millennia. For instance, the oldest modern PA, the Yosemite National Park, has been considered sacred and protected as such by local people for many centuries, the Bogd Khan Mountain in Mongolia has been protected since the twelfth century and a Buddhist temple at Nikko (Japan) has been constructed 1100 years ago (see Dudley et al. 2005 for details and other examples). Like OECMs at large, it has been suggested that SNS may constitute a large network of "informal" PA (Dudley et al. 2009), potentially reinforcing the official PA networks (Frascaroli et al. 2019) and contributing to conservation at global scale. Indeed, it has been reported that SNS have the same, or even higher, levels of species richness as comparable areas and even official reserves (see e.g. Bhagwat et al. 2005a,b,c; Brown et al. 2006a,b; Boadi et al. 2017). Moreover, SNS sometimes act as refugia for endemic, threatened, rare or specialist species (see e.g. Gunaga et al. 2013; Kühnert et al. 2019) and preserve old-growth trees and forest patches (see e.g. Salick et al. 2007; Tiwari et al. 2010a,b; Frascaroli et al. 2016a,b; Stara et al. 2015). In some cases, SNS can also represent the only natural or seminatural patches of habitat within highly modified landscapes (Dudley et al. 2010). SNS are found in association with both indigenous and mainstream faiths and in all continents, except for Antarctic (Dudley et al. 2005). However, most of the research concerning SNS has so far focused on Africa and Asia (Dudley et al. 2010).

Despite the growing awareness of the importance of SNS for both conservation and local livelihoods, no systematic review based on quantitative or semi-quantitative methods has been published on the topic to date. Existing syntheses have introduced SNS to the scientific and conservation communities and demonstrated their significance in a wide range 
of contexts (Bhagwat and Rutte 2006; Dudley et al. 2005, 2010). While classic literature reviews have provided major insights, enabling syntheses and highlighting various gaps in our knowledge, the growing number of primary studies offers in addition an opportunity to deploy techniques of systematic review and meta-analysis. Systematic reviews can increase transparency, reproducibility and objectivity by applying strict guidelines throughout the whole review process (Pullin and Stewart 2006; Haddaway et al. 2015). Meta-analyses further develop such results by investigating statistically the size, direction and significance of various treatments across multiple studies (Vetter et al. 2013).

In the present work, we carry out the first review that applies a systematic approach and semi-quantitative methods to address the following question: do SNS worldwide have significant benefits for biodiversity conservation, compared to surrounding areas? We take the comparison of SNS with nearby non-sacred areas as fundamental to objectively evaluate their effectiveness in delivering area-based conservation of nature (see Coetzee et al. 2014 for a similar case). In particular, we asked if the reported effects of SNS on biodiversity varies across: (1) continents; (2) taxa; (3) biodiversity measures. We investigated these three facets through systematic review, while collecting evidence on the state-of-art literature on SNS and paving the way to future evidence-based synthesis.

\section{Methods}

\section{Data collection}

To carry out the review, we followed the guidelines proposed by Pullin and Stewart (2006) for reviews in conservation and environmental management. A literature search was performed using Scopus Database (last access on May 27, 2019). The search string was composed of 'OR' and 'AND' statements combining key terms like "biological conservation" and "biodiversity" with SNS-related terms, such as "shrine", "temple" and "church" (Online Appendix A). We limited our search to peer-reviewed articles and book chapters (henceforth "papers"). We excluded conference papers, as they often consist of still partial, temporary or non-peer reviewed data (for the same reasons we removed records classified in Scopus as "note", "erratum", "letter" and "short survey"). No limitations were placed on the year or country of publication. The literature search provided 2750 unique results that were screened by title and abstract to remove entries clearly not relevant to the review (Online Appendix B). This left a set of 473 papers, 95 of which, however, could not be retrieved. We thus read the full-text of the 378 resulting papers and chose only papers in English offering systematic comparisons between SNS and Reference Sites (RS) either of taxonomical diversity indices or of vegetation structure measurements or both. Based on these criteria, a final pool of 27 studies were identified as eligible for the review (see Sect. 'Data sources" for the full list of references). For each study we extracted publication metadata, geographical location (or its approximate centroid) and the taxonomic group investigated. Taxa were aggregated at high taxonomical level, distinguishing among vertebrates, invertebrates, plants and fungi. As lichens appeared in only one study, we decided to group them with fungi. We finally determined the biome in which each study was located, based on the WWF Ecoregion Map (Olson et al. 2001). Also, it has to be noted that the number of SNS studied within each paper was rather varied (up to 32, with a median of 6).

The selected studies provided very heterogeneous information. To keep the greatest portion of available knowledge while at the same time enabling meaningful comparisons 
between such different studies, we opted for carrying out a semi-quantitative evaluation through the vote counting method (Koricheva et al. 2013). Based on this method, different outcomes of the tested comparisons are categorized as having an effect that is significantly positive (+), significantly negative (-) or non-significant ( 0 , henceforth "neutral effect"). Hence, each comparison between SNS and RS casts a "vote" and the numbers of votes are counted. In order to minimize subjectivity and enhance reproducibility, we chose to include in the vote counting only comparisons whose statistical significance was reported in the studies or could be determined based on the data. Comparisons stated as marginally significant $(0.05<p<0.10)$ were still retained as significant. When $p$-values were not reported, we tried to use relevant data, such as raw or mean values, sample sizes, and confidence intervals, to calculate the significance of the effect. When $p$-values were neither reported nor retrievable on the basis of other available information, we excluded the comparisons from the vote counting. Similarly, we did not consider multiple comparisons on the same data that were not followed by appropriate post-hoc testing (e.g., Bonferroni). Finally, given the large heterogeneity of metrics in the pool of target studies, we reclassified them into a set of 6 classes (Online Appendix C) and we excluded metrics that could not be reclassified, resulting in 131 comparisons (given that for one study we can have more than one comparisons). Descriptive data about the 27 selected papers as well as the 131 comparisons can be found in Online Appendix D.

We divided the retrieved comparisons into classes according to different aspects of biodiversity sensu lato. The first three classes ("taxonomic diversity", "evenness" and "beta diversity") are related to typical biodiversity measures. In particular, taxonomical diversity is related to local diversity irrespective of taxonomical resolution and aims at measuring that component of diversity that is the number of different classes without accounting for their relative sizes, which in turn is measured by the evenness. As in our dataset Shannon's $\mathrm{H}$ was always employed along with species richness and in order not to use redundant comparisons, we chose to use Shannon's $\mathrm{H}$ as a proxy of evenness when a direct measure of evenness (like Pielou's E o Simpson's 1-D) was absent, otherwise we discarded it. "Policy species" gathers all metrics related to threatened, rare or endemic taxa. "Vegetation structure" is made up by metrics calculated on stem characteristics, such as mean basal area, mean diameter at breast height and number of stems per unit area, and is meant to be a proxy of mature vegetation. Finally, within "cultural use" we included all the aspects related to the use of biodiversity resources, such as medicinal or culturally important species. This is also referred as or considered part of the Traditional Environmental Knowledge (TEK) of local communities. Although these two last classes (i.e. "vegetation structure" and "cultural use") are not biodiversity measures strictly speaking, we considered them as complementary measures of biodiversity and conservation potential. Indeed, both mature vegetation and TEK are often related to habitat conservation or traditional sustainable management.

\section{Statistical analyses}

To assess whether the positive, negative and neutral effects of SNS occurred in statistically significant proportions, we used a multinomial exact test. This kind of test implies that the response variable is a categorical variable with more than two values. In our case, the observed effects were: positive, negative and neutral (no effect). The observed frequencies of each value are then compared against a set of expected frequencies. We tested our observations against the assumption that positive, negative and neutral effects of SNS would 
have equal odds to occur. We tested both for all the recorded effects together and for separate subsets, defined on the basis of relevant variables: the continent where the effect of SNS was investigated; the taxonomic group under scrutiny; and the class of metrics used in the comparison between SNS and RS. For each test, we calculated the log-likelihood ratio statistic (LLR) and its relative $p$-value. We chose this metric given its demonstrated advantages over more popular alternatives, such as Pearson's Chi-square (Kotze and Gokhale 1980).

To test further which effects significantly deviate from their expected frequencies in instances where the multinomial exact test was significant, we applied exact binomial test (McDonald 2014). This test is based on the same logic as the exact multinomial but is applied to categorical variables with two possible values. We thus tested the observed frequency of each effect against the pooled frequencies of the other two, and an expected odd ratio 1:2. Since this procedure entails multiple comparisons from the same sample data, we applied Holm correction (Holm 1979) to the resulting $p$-values. This is similar to a Bonferroni correction but retains slightly higher statistical power, while still controlling the overall Type I error rate (Olejnik et al. 1997). Tests were performed in $\mathrm{R}$ version 3.6.3 ( $\mathrm{R}$ Core Team 2020) with the package XNomial v 1.0.4 (Engels 2015), while graphical outputs were produced with ggplot2 (Wickham 2016), patchwork (Pedersen 2020), ggthemes (Arnold 2019), ggnewscale (Campitelli 2020), sf (Pebesma 2018) and rnaturalearth (South 2017).

\section{Results}

\section{Distribution across continents and taxa}

The geographical distribution of the study areas investigated in the 27 papers eligible for systematic review was highly uneven (Fig. 1a), as 8 studies focused on the Kodagu District (India) and another 8 on West Africa. Overall, we found 13 papers related to SNS located in Asia, 11 in Africa and only 3 papers related to SNS in Europe (Fig. 1b). The final pool did not yield any paper concerning SNS from Oceania or Americas. India, Ghana and China were the only countries for which more than 1 paper was found, with
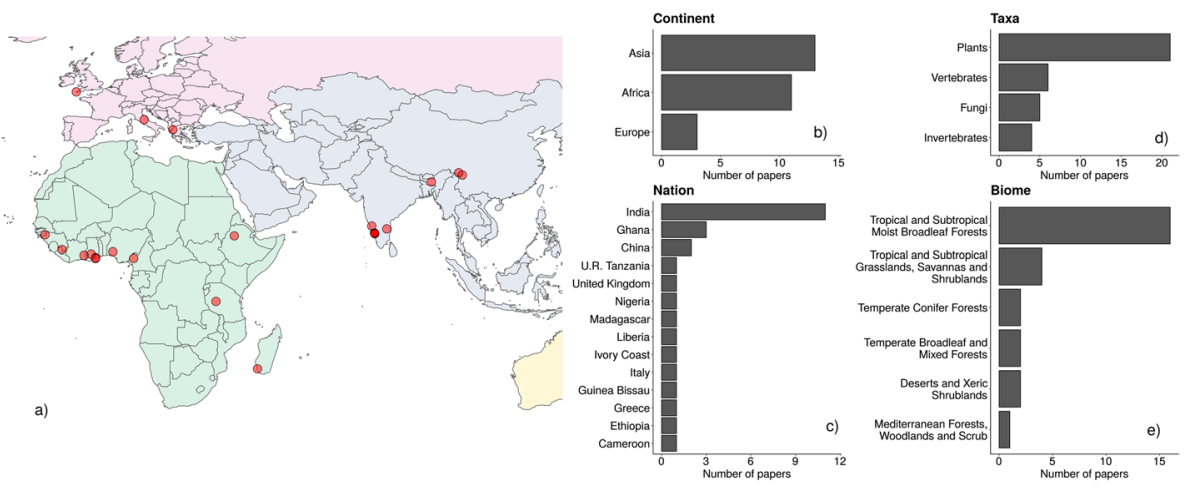

Fig. 1 Descriptive statistics of selected papers $(n=27)$. a Geographical distribution of study areas. b Papers by continent. $\mathbf{c}$ Papers by country. $\mathbf{d}$ Papers by taxa. e Papers by biome 
11, 3 and 2 papers, respectively (Fig. 1c). The distribution of taxa studied within papers was dominated by plants $(n=21)$, followed by vertebrates, fungi and invertebrates $(n=6,5$ and 4, respectively; Fig. 1d). In 5 papers a multi-taxa approach was employed. The tropical and subtropical moist broadleaf forests biome, finally, was by far the most common biome $(n=16)$, whereas other biomes were more scarcely represented or not represented at all in the pool of papers (Fig. 1e).

\section{Effects of SNS}

Overall comparisons extracted from our pool of papers showed that SNS had positive or neutral effects in the vast majority of cases, whereas negative effects accounted for only ca. $10 \%$ of the total (Fig. 2). Dividing the comparisons by continent, Europe had the largest proportion of positive effects and the smallest proportion of negative effects (about 55\% and 5\%, respectively), with Africa and Asia also showing similar patterns. While vertebrates, plants and fungi had similar patterns to all comparisons grouped together, invertebrates stood out as they had no positive effects. When considering different types of indicator, vegetation structure and cultural uses had no recorded negative effects and the former even had positive effects in ca. $70 \%$ of cases.

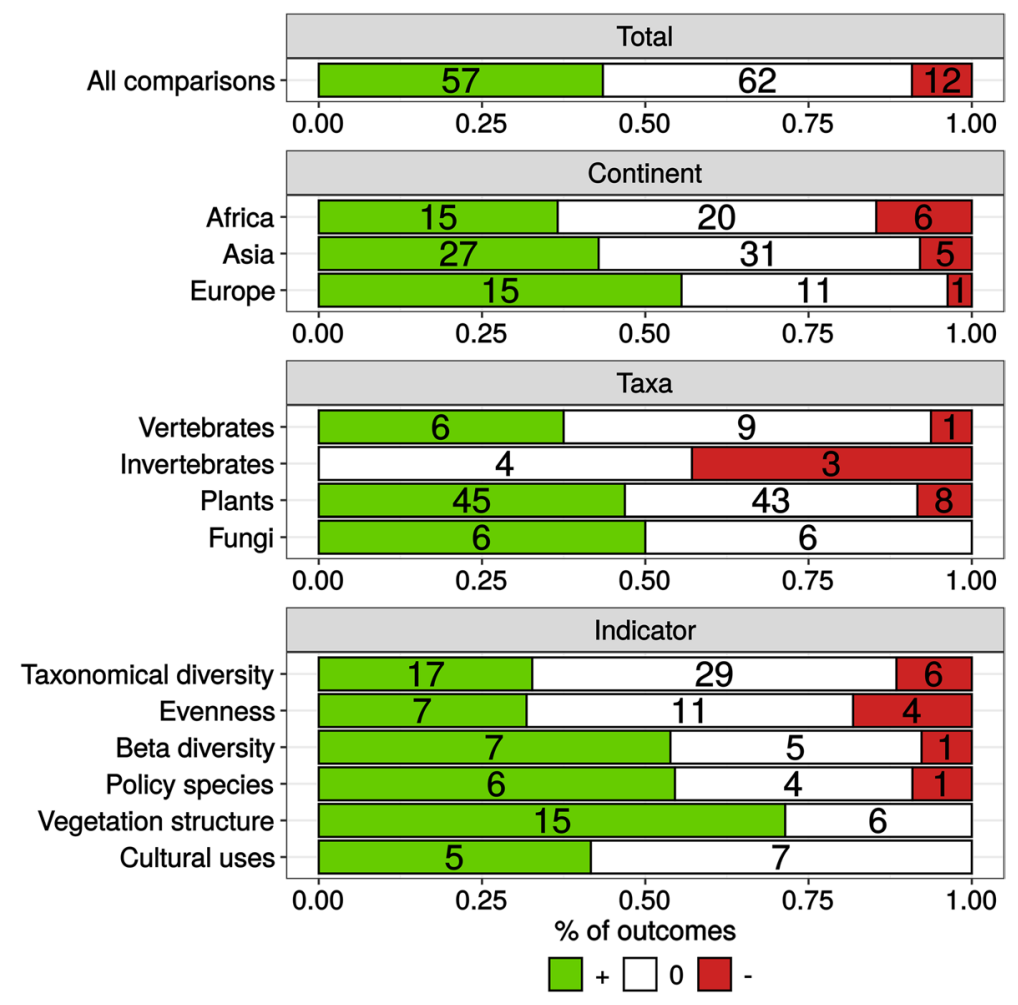

Fig. 2 Summary of the effect of SNS on biodiversity conservation. Bar-plots show the distribution of positive (+), negative (-) and neutral (0) effects according to different classifications: Total comprises shows all the comparisons indiscriminately, Continent and Taxa show comparisons by geographical and taxonomical classes respectively 
Multinomial tests for all groups of comparisons were statistically significant (Table 1), whereas post-hoc binomial tests were significant only in a limited number of cases. In particular, for all comparisons the pooled positive and neutral effects were significantly more than expected under the null hypothesis and negative effects were significantly less. When looking at comparisons split by continent, negative effects were always less than expected, while in the case of Europe we also found more positive effects and in Asia we found more neutral effects. Plants and fungi showed significantly fewer negative effects, with plants also displaying more positive and neutral effects than expected under null hypothesis. Finally, taxonomical diversity, vegetation structure and cultural uses had fewer negative outcomes than expected under the null hypothesis, with first also showing more cases with neutral effects and the second more positive effects.

\section{Discussion}

Interest in SNS from a conservation perspective has been growing over the years. However, there have been only scant efforts at systematising available knowledge and drawing key messages regarding their conservation effectiveness at a global scale. Despite the limited number of studies found with suitable criteria, our results somehow support the view, already advanced in a number of local studies (see e.g. Bossart et al. 2006a, b; Ambinakudige and Sathish 2009; Brandt et al. 2013; Frascaroli et al. 2016a, b; Nopper et al. 2017; Avtzis et al. 2018a, b; Shepheard-Walwyn and Bhagwat 2018a, b) and earlier overviews

Table 1 Summary of the effect of SNS on biodiversity conservation displayed as results of Multinomial and Binomial Post-Hoc post hoc tests

\begin{tabular}{llrllll}
\hline Class & Group & $N$ & $\begin{array}{l}p \text {-value multi- } \\
\text { nomial test }\end{array}$ & $\begin{array}{l}p \text {-value posi- } \\
\text { tive effects }\end{array}$ & $\begin{array}{l}p \text {-value neu- } \\
\text { tral effects }\end{array}$ & $\begin{array}{l}p \text {-value } \\
\text { negative } \\
\text { effects }\end{array}$ \\
\hline Total & All comparisons & 131 & $<\mathbf{0 . 0 0 1}$ & $\mathbf{0 . 0 1 2} \uparrow$ & $\mathbf{0 . 0 0 2} \uparrow$ & $<\mathbf{0 . 0 0 1} \downarrow$ \\
Continent & Africa & 41 & $<\mathbf{0 . 0 0 1}$ & 0.621 & 0.089 & $\mathbf{0 . 0 3 6} \downarrow$ \\
& Asia & 63 & $<\mathbf{0 . 0 0 1}$ & 0.108 & $0.02 \uparrow$ & $<\mathbf{0 . 0 0 1} \downarrow$ \\
& Europe & 27 & $<\mathbf{0 . 0 0 1}$ & $\mathbf{0 . 0 4 4} \uparrow$ & 0.416 & $\mathbf{0 . 0 0 1} \downarrow$ \\
Taxa & Vertebrates & 16 & $\mathbf{0 . 0 0 2}$ & 0.791 & 0.123 & 0.088 \\
& Invertebrates & 7 & $\mathbf{0 . 0 1 6}$ & 0.312 & 0.458 & 0.691 \\
& Plants & 96 & $<\mathbf{0 . 0 0 1}$ & $\mathbf{0 . 0 0 9} \uparrow$ & $\mathbf{0 . 0 1 7} \uparrow$ & $<\mathbf{0 . 0 0 1} \downarrow$ \\
& Fungi & 12 & $\mathbf{0 . 0 0 2}$ & 0.455 & 0.455 & $\mathbf{0 . 0 3 5} \downarrow$ \\
Indicator & Taxonomical diversity & 52 & $<\mathbf{0 . 0 0 1}$ & 1 & $\mathbf{0 . 0 0 2} \uparrow$ & $\mathbf{0 . 0 0 2} \downarrow$ \\
& Evenness & 22 & $\mathbf{0 . 0 0 7}$ & 1 & 0.334 & 0.351 \\
& Beta diversity & 13 & $\mathbf{0 . 0 0 6}$ & 0.279 & 0.77 & 0.22 \\
& Policy species & 11 & $\mathbf{0 . 0 1 3}$ & 0.391 & 0.759 & 0.345 \\
& Vegetation structure & 21 & $<\mathbf{0 . 0 0 1}$ & $\mathbf{0 . 0 0 1} \uparrow$ & 0.818 & $<\mathbf{0 . 0 0 1} \downarrow$ \\
& Cultural uses & 12 & $\mathbf{0 . 0 0 1}$ & $0 . .546$ & $0 . .142$ & $\mathbf{0 . 0 3 5} \downarrow$ \\
\hline
\end{tabular}

Each row represents a different group arising in a class of comparisons, classes are grouped according to different classifications (e.g.i.e. "ClassGroup"). The first row shows all comparisons grouped together indiscriminately. $N$ is the number of comparisons. Bold numbers displaysdisplay significant results $($ alpha $=.05)$. Arrows show the direction of significant binomial post -hoc tests, up-arrows mean "more than expected", down-arrows mean "less than expected" 
(Bhagwat and Rutte 2006; Dudley et al. 2005, 2010), that SNS have positive effects on biodiversity across continents and geographical settings. At the same time, our review also underscores that the quantitative research to date has been limited to relatively few areas and taxa, resulting in evident knowledge gaps.

In the first place, the final pool of papers showed strongly uneven distributions, both spatially and taxonomically. As Dudley et al. (2010), we also found that research has largely focused on two main regions, namely the West-Central portions of India and Africa. These two areas approximate the Western African Forests and the Western Ghats of India, two global hotspots of biodiversity (Myers et al. 2000). At the same time, no papers from Americas, Oceania and large portions of Asia were retrieved. This limited geographical range is likely to hide part of the story, as there are indications that important SNS also occur in those macro-areas, although they have not been so far studied from a quantitativeecological perspective.

Similarly, we detected a strong bias towards plants, partly reflecting a common taxonomical bias found in ecological and conservation research. Notably, plants are easierand probably cheaper (Geijzendorffer et al. 2016) — to study than many other taxa, as they can be surveyed with relatively little time and resources and also as they already are much better known than other taxa. Moreover, many SNS are quite small and hence likely more successful in conserving plant species rather than animal species, especially medium to large sized animals (Nilsson and Ericson 1997; Parker 2012). This in turns could have potentially influenced scientists planning to study SNS, catalysing their focus towards plants. Several high-rank taxa which are widely studied in ecology and conservation were totally absent (e.g. fishes) or present in only one study (e.g. lichens), while the microbiota were not studied at all. These spatial and taxonomical biases that we recorded are likely due to the fact that the literature on the topic is small and largely contributed by a restricted group of scientists, specialized in the geographical areas and taxa in question. At the same time, we cannot rule out the possibility that the review protocol we adopted may have contributed to partly exacerbating those biases. For example, some papers focusing on additional geographical areas and taxa were excluded from our final pool because they did not satisfy some inclusion criteria (e.g. Castro and Aldunate 2003; Dafni 2006; García-Frapolli et al. 2007) or they were not present in Scopus at all (e.g. Deb et al. 1997). Indeed, including the grey literature in future synthesis, while further enlarging the inclusion criteria, will definitely help gaining a broader and more detailed comprehension of the phenomenon. We also think that a public call for scientists and practitioners could help catalyse the attention and offer the opportunity to collect larger and more structured datasets.

In the second place, we noted some methodological limitations in the literature, which could be overcome in relatively easy ways. For example, some contributions have surveyed elements of biodiversity at SNS without comparing them with appropriate RS. While studies of this kind can have very high value from the point of view of community ecology, they do not offer a possibility of testing specific hypotheses to benchmark the conservation effect of SNS compared with neighboring areas. In other cases, the possibility to quantitatively synthesize available knowledge can be inhibited by missing information about the statistics employed, such as means and standard errors, or, more generally, by the unavailability of primary data.

In the third place, details about belief systems, management and governance would be key to understand the mechanisms whereby SNS deliver successful conservation, and evaluate their resilience or possible threats in the future (Dudley et al. 2005). Previous research has highlighted how deeply belief systems can affect the relationship between local communities and their environment. Also, different religions have different potential 
to influence in situ conservation (Mikusiński et al. 2013). Systematic data would enable the testing of possible relations between different faiths (e.g. monotheistic religions, animistic systems) and specific conservation outcomes. However, even basic details about belief systems are frequently omitted in the ecological literature on SNS. Similarly, governance regimes regulate the way communities manage their environmental resources. It has been suggested that one of the key characteristics of SNS is to include a set of mechanisms that contribute to enforcing effective and environmentally beneficial governance (Rutte 2011). However, no studies to date have systematically looked into the governance and management created under SNS and, even worse, often this information is completely omitted from research papers on the topic. This is a gap that should be urgently addressed in future interdisciplinary research.

Besides these limitations, our results provided overall confirmation of the biological importance of SNS worldwide. Indeed, all multinomial tests were statistically significant as well as a part of the post-hoc tests, indicating that SNS positively affect local biodiversity. These effects may be the outcomes of both unique environmental characteristics of SNS, as they often overlap with outstanding natural features (see e.g. Anderson et al. 2005; Frascaroli et al. 2016a, b), and particular cultural factors and governance regimes, which regulate SNS use and prevent over-exploitation (e.g., Rutte 2011; Marini Govigli et al. 2020). Moreover, while our analysis yielded no definitive proof that SNS are always beneficial to biodiversity, it produced very clear evidence that only seldom they are detrimental (for example, acting as sources of invasive species; see e.g., Liu et al. 2013), despite being areas primarily dedicated to cultural uses. Indeed, in the overall pool of comparisons, positive and neutral effects were significantly more frequent and negative effects significantly less than expected. Similarly, when post-hoc tests resulted in significant outcomes, which occurred in less than half of all cases, positive and neutral effects were always observed more frequently than expected under the null hypothesis, while negative effects were always observed less frequently. The fact that the majority of the post hoc tests was not significant, in contrast, may indicate the lack of a clear trend in the results or suggest that the small sample size was enough to catch some signal at first, but insufficient to confirm the results when checking for the single effects.

Comparisons grouped by continent showed that Africa had the largest proportion of negative effects, although also in this case they remained significantly less frequent than expected, while Asia and Europe showed higher proportions of neutral effects and positive effects, respectively. This is an interesting finding, given that SNS are commonly thought of in connection with indigenous or non-Western context. The evidence we reviewed, in contrast, indicates that they have a significant positive effect on biodiversity also in relatively modernized areas of Europe. A possible explanation may be that the studies on SNS in Europe are often located in relatively less populated and accessible areas, e.g. Central Apennines (Frascaroli et al. 2016a, b) and Epirus (Avtzis et al. 2018a, b), while papers from Asia are mostly from Kodagu District in India, which has a moderately high human density. Therefore, we could hypothesise that geographical isolation has favored a continuity of traditional management and governance of those European SNS, although in a context of broader secularization, with positive repercussions on their biodiversity. Nonetheless, we underline that only three studies from Europe were retrieved, hence further evidence is needed to confirm our results and draw general conclusions.

Results by taxa showed that SNS have a significantly positive effect on plants. While the reason for this pattern is not clear, the discrepancies among significant results for different taxa is likely due to the different sample sizes. Moreover, no positive effects were found for invertebrates, although this result was not statistically significant due to the small number 
of observations. However, there could also be ecological reasons for the lack of positive effects on invertebrates, as groups like butterflies or nematodes, for instance, are known to produce very different assemblages as a response to the type of management and disturbance (see e.g. Hamer et al. 1997; Fu et al. 2000).

Results by type of metrics demonstrated that SNS affect mostly the number of taxa, vegetation structure and cultural uses. Available evidence suggests that all these patterns are likely to be dependent on the activities typically allowed or forbidden at SNS, often codified in the forms of taboos (Colding and Folke 2001). Stara et al. (2016), for example, reported that grazing and hunting as well as deadwood and non-timber products collection are often permitted at SNS in Epirus (Greece), whereas bans and restrictions are mostly connected to trees. A similar situation has been described with regards to the SNS of Central Italy (Frascaroli et al. 2016a, b). In both cases, the traditional and extensive use of these sites is likely to have produced a moderate degree of disturbance, which is known to increase the local number of taxa, that is, the so called "intermediate disturbance hypothesis" (Connell 1979). Similarly, taboos related to trees are likely to have promoted the conservation of mature vegetation stands, explaining the significant effect found for vegetation structure (Marini Govigli et al. 2020). Finally, the possibility to collect forest and understory products in a culturally prominent area can explain the persistence of TEK and cultural uses of biodiversity at SNS. While these examples are both from SNS in Europe, the importance of resource-related taboos and collection of useful plants is far from limited to European SNS, having been similarly recorded in other different contexts such as, for example, India (Ormsby 2013) and the Himalaya (Salick et al. 2007).

Overall, our results newly underline the importance of recognizing and possibly ratifying the effectiveness of SNS for area-based conservation, while at the same time considering that they are culturally sensitive areas whose primary purpose is not conservation. This would foster the application of appropriate policies and measures (IUCN-WCPA 2019), while addressing such aims as increasing the coverage of rare or important ecosystems, supporting the conservation of threatened species and enhancing the connectivity of PA networks, among the others. Beliefs and practices associated with SNS should be part of any form of official recognition or institutionalization, as research shows that they are often key to driving the biodiversity patterns found in these areas. In this perspective, the broader framework currently developed with regards to OECMs can serve as a valuable example on which to build, to ratify the role of SNS without assimilating them to PA in the classical sense. At the same time, our review also shows that our knowledge of SNS needs to be systematized, and a number of gaps filled, before the conservation potential of SNS can be fully understood and recognized.

Firstly, it is pivotal to undertake large scale surveys of SNS networks at a national or regional scale, as done for instance by Reynolds et al. (2016) or Frascaroli et al. (2019), to acquire a better sense for the extent of those networks and their distribution across biomes and altitudinal gradients. Moreover, such surveys would lay the foundation for an integrated conservation planning, which simultaneously accounts for PA, OECMs and SNS.

Secondly, it would be desirable to elaborate standardized protocols for future studies of SNS (see Borges et al. 2018 for an analogous case). Such protocols should concern the sampling of biological communities, the characterization and classification of SNS (e.g., based on their geographical extent, ecological characteristics, belief systems), as well as the analysis of governance and management mechanisms currently in place. This information would help us disentangle the effect of SNS on different types of organisms across faiths and, likely more importantly, management types, while systematically collecting evidence for future syntheses. 
Finally, a number of local studies should address the taxonomic and geographical gaps evidenced by our reviews, to understand whether SNS contribute to conservation of other taxa than just plants and on a truly global scale. In particular, studies from Americas and Oceania are lacking and from high latitudes in general, as well as studies on many animal groups, fungi and other microorganisms. These efforts would advance our understandings of SNS and help maximize their contribution to area-based conservation schemes.

\section{Conclusions and outlook for future research}

In light of the growing recognition of SNS and OECMs in conservation policy and approaches globally, this study aimed at providing the first systematic review about the effects of SNS on biodiversity conservation. Out of 2750 papers extracted, we found 27 that met our criteria for quantitative information and analysis of biodiversity or vegetation structure. These came from studies scattered across Africa, Asia and Europe and investigated plants, animals and fungi. According to our analyses and based on a vote-counting approach, the evidence that SNS improve biodiversity conservation is quite strong, although this is not a conclusive proof given the small number of studies and their spatially-unbalanced distribution. Also, the research on the topic has left large geographical areas unexplored, while studying predominantly plants. New efforts towards filling these knowledge gaps and towards improving our broader knowledge of SNS are urgent, to maximize their synergy with larger conservation schemes.

Supplementary Information The online version contains supplementary material available at https://doi. org/10.1007/s10531-021-02296-3.

Funding Open access funding provided by Alma Mater Studiorum - Università di Bologna within the CRUI-CARE Agreement. The research was supported by the Ministry of Education, University and Research, Italy (MIUR) through PRIN project 2015P8524C "Biodiversity and ecosystem services in sacred natural sites (BIOESSaNS)".

Data availability The authors confirm that the data supporting the findings of this study are available within the article and its supplementary materials.

Code availability Not applicable.

\section{Declarations}

Conflict of interest Authors have no competing interests.

Ethical approval Not applicable.

Consent to participate Not applicable.

Open Access This article is licensed under a Creative Commons Attribution 4.0 International License, which permits use, sharing, adaptation, distribution and reproduction in any medium or format, as long as you give appropriate credit to the original author(s) and the source, provide a link to the Creative Commons licence, and indicate if changes were made. The images or other third party material in this article are included in the article's Creative Commons licence, unless indicated otherwise in a credit line to the material. If material is not included in the article's Creative Commons licence and your intended use is not permitted by statutory regulation or exceeds the permitted use, you will need to obtain permission directly from the copyright holder. To view a copy of this licence, visit http://creativecommons.org/licenses/by/4.0/. 


\section{References}

Ambinakudige S, Sathish BN (2009) Comparing tree diversity and composition in coffee farms and sacred forests in the western ghats of India. Biodivers Conserv 18:987-1000. https://doi.org/10. 1007/s10531-008-9502-5

Anderson DM, Salick J, Moseley RK, Xiaokun O (2005) Conserving the sacred medicine mountains: a vegetation analysis of Tibetan sacred sites in Northwest Yunnan. Biodivers Conserv 14:3065-3091. https://doi.org/10.1007/s10531-004-0316-9

Arnold JB (2019) ggthemes: extra themes, scales and geoms for 'ggplot2'. R package version 4.2.0. https://CRAN.R-project.org/package=ggthemes

Avtzis DN, Stara K, Sgardeli V, Betsis A, Diamandis S, Healey DN, Kapsalis E, Kati V, Korakis G, Marinigovigli V, Monokrousos N, Muggia L, Nitsiakos V, Papadatou E, Papaioannou H, Rohrer A, Tsiakiris R, van Houtan KS, Vokou D, Wong JLG, Halley JM (2018a) Quantifying the conservation value of sacred natural sites. Biol Cons 222:95-103. https://doi.org/10.1016/j.biocon.2018.03.035

Baillie JEM, Zhang Y-P (2018) Space for nature. Science 361(6407):1051. https://doi.org/10.1126/scien ce.aau 1397

Bhagwat SA, Rutte C (2006) Sacred groves: potential for biodiversity management. Front Ecol Environ 4(10):519-524. https://doi.org/10.1890/1540-9295(2006)4[519:SGPFBM]2.0.CO;2

Bhagwat SA, Kushalappa CG, Williams PH, Brown ND (2005a) A landscape approach to biodiversity conservation of sacred groves in the Western Ghats of India. Conserv Biol 19:1853-1862. https:// doi.org/10.1111/j.1523-1739.2005.00248.x

Boadi S, Nsor CA, Yakubu DH, Acquah E, Antobre OO (2017) Conventional and indigenous biodiversity conservation approach: a comparative study of Jachie sacred grove and Nkrabea forest reserve. Int J for Res. https://doi.org/10.1155/2017/1721024

Borges PAV, Cardoso P, Kreft H, Whittaker RJ, Fattorini S, Emerson BC, Gil A, Gillespie RG, Matthews TJ, Santos AMC, Steinbauer MJ, Thébaud C, Ah-Peng C, Amorim IR, Aranda SC, Arroz AM, Azevedo JMN, Boieiro M, Borda-De-água L, Carvalho JC, Elias RB, Fernández-Palacios JM, Florencio M, González-Mancebo JM, Heaney LR, Hortal J, Kueffer C, Lequette B, MartínEsquivel JL, López H, Lamelas-López L, Marcelino J, Nunes R, Oromí P, Patiño J, Pérez AJ, Rego C, Ribeiro SP, Rigal F, Rodrigues P, Rominger AJ, Santos-Reis M, Schaefer H, Sérgio C, Serrano ARM, Sim-Sim M, Stephenson PJ, Soares AO, Strasberg D, Vanderporten A, Vieira V, Gabriel R (2018) Global Island Monitoring Scheme (GIMS): a proposal for the long-term coordinated survey and monitoring of native island forest biota. Biodivers Conserv 27(10):2567-2586. https://doi.org/ 10.1007/s10531-018-1553-7

Bossart JL, Opuni-Frimpong E, Kuudaar S, Nkrumah E (2006a) Richness, abundance, and complementarity of fruit-feeding butterfly species in relict sacred forests and forest reserves of Ghana. Biodivers Conserv 15:333-359. https://doi.org/10.1007/s10531-005-2574-6

Brandt JS, Wood EM, Pidgeon AM, Han LX, Fang Z, Radeloff VC (2013) Sacred forests are keystone structure for forest bird conservation in southwest China's Hymalayan Mountains. Biol Conserv 166:34-42. https://doi.org/10.1016/j.biocon.2013.06.014

Brown N, Bhagwat S, Watkinson S (2006a) Macrofungal diversity in fragmented and disturbed forests of the Western Ghats of India. J Appl Ecol 43:11-17. https://doi.org/10.1111/j.1365-2664.2005.01107.x

Campitelli E (2020) ggnewscale: multiple fill and colour scales in 'ggplot2'. R package version 0.4.1. https://CRAN.R-project.org/package=ggnewscale

Castro V, Aldunate C (2003) Sacred mountains in the highlands of the south-central andes. Mt Res Dev 23(1):73-79. https://doi.org/10.1659/0276-4741(2003)023[0073:SMITHO]2.0.CO;2

Coetzee BWT, Gaston KJ, Chown SL (2014) Local scale comparisons of biodiversity as a test for global protected area ecological performance: a meta-analysis. PLoS ONE 9(8):e105824. https://doi.org/10. 1371/journal.pone.0105824

Colding J, Folke C (2001) Social taboos: "invisible" systems of local resource management and biological conservation. Ecol Appl 11(2):584-600. https://doi.org/10.1890/1051-0761(2001)011[0584:STISOL] 2.0.CO;2

Connell JH (1979) Intermediate-disturbance hypothesis. Science 204(4399):1345. https://doi.org/10.1126/ science.204.4399.1345

Dafni A (2006) On the typology and the worship status of sacred trees with a special reference to the middle east. J Ethnobiol Ethnomed 2:26. https://doi.org/10.1186/1746-4269-2-26

Deb D, Deuti K, Malhotra KC (1997) Sacred grove relics as bird refugia. Curr Sci 73(10):815-817

Díaz S, Settele J, Brondízio E, Ngo H, Guèze M, Agard J, Arneth A, Balvanera P, Brauman K, Butchart S, Chan K, Garibaldi L, Ichii K, Liu J, Subrmanian S, Midgley G, Miloslavich P, Molnár Z, Obura D, Pfaff A, Polasky S, Purvis A, Razzaque J, Reyers B, Chowdhury R, Shin Y, Visseren-Hamakers I, 
Wilis K, Zayas C (2019) Summary for policymakers of the global assessment report on biodiversity and ecosystem services of the Intergovernmental Science-Policy Platform on Biodiversity and Ecosystem Services. https://uwe-repository.worktribe.com/output/1493508. Accessed May 2020

Dinerstein E, Joshi AR, Vynne C, Lee ATL, Pharand-Deschênes F, França M, Fernando S, Birch T, Burkart K, Asner GP, Olson D (2020) A “global safety net” to reverse biodiversity loss and stabilize Earth's climate. Sci Adv 6(36):eabb2824. https://doi.org/10.1126/sciadv.abb2824

Dudley N, Higgins-Zogib L, Mansourian S (2005) Beyond belief: linking faiths and protected areas for biodiversity conservation. WWF and Alliance of Religions and Conservation, Gland

Dudley N, Higgins-Zogib L, Mansourian S (2009) The links between protected areas, faiths, and sacred natural sites. Conserv Biol 23(3):568-577. https://doi.org/10.1111/j.1523-1739.2009.01201.x

Dudley N, Bhagwat S, Higgins-Zogib L, Lassen B, Verschuuren B, Wild R (2010) Conservation of biodiversity in sacred natural sites in Asia and Africa: a review of the scientific literature. In: Verschuuren B, Wild R, Mcneely JA, Oviedo G (eds) Sacred natural sites: conserving nature \& culture. Earthscan, London, pp 19-32

Engels B (2015) XNomial: exact goodness-of-fit test for multinomial data with fixed probabilities. R package version 1.0.4. https://CRAN.R-project.org/package $=$ XNomial

Frascaroli F, Bhagwat S, Guarino R, Chiarucci A, Schmid B (2016a) Shrines in Central Italy conserve plant diversity and large trees. Ambio 45(4):468-479. https://doi.org/10.1007/s13280-015-0738-5

Frascaroli F, Zannini P, Acosta ATR, Chiarucci A, D’Agostino M, Nascimbene J (2019) Sacred natural sites in Italy have landscape characteristics complementary to protected areas: Implications for policy and planning. Appl Geogr 113:102100. https://doi.org/10.1016/j.apgeog.2019.102100

Fu S, Coleman DC, Hendrix PF, Crossley DA (2000) Responses of trophic groups of soil nematodes to residue application under conventional tillage and no-till regimes. Soil Biol Biochem 32(11-12):17311741. https://doi.org/10.1016/S0038-0717(00)00091-2

García-Frapolli E, Ayala-Orozco B, Bonilla-Moheno M, Espadas-Manrique C, Ramos-Fernández G (2007) Biodiversity conservation, traditional agriculture and ecotourism: Land cover/land use change projections for a natural protected area in the northeastern Yucatan Peninsula, Mexico. Lands Urban Plan 83(2-3):137-153. https://doi.org/10.1016/j.landurbplan.2007.03.007

Geijzendorffer IR, Targetti S, Schneider MK, Brus DJ, Jeanneret P, Jongman RH, Knotters M, Viaggi D, Angelova S, Arndorfer M, Bailey D, Balázs K, Báldi A, Bogers MMB, Bunce RGH, Choisis J-P, Dennis P, Eiter S, Fjellstad W, Friedel JK, Gomiero T, Griffioen A, Kainz M, Kovács-Hostyánszki A, Lüscher G, Moreno G, Nascimbene J, Paoletti MG, Pointereau P, Sarthou J-P, Siebrecht N, Staritsky I, Stoyanova S, Wolfrum S, Herzog F (2016) How much would it cost to monitor farmland biodiversity in Europe? J Appl Ecol 53:140-149. https://doi.org/10.1111/1365-2664.12552

Gunaga S, Rajeshwari N, Vasudeva R (2013) Tree diversity and disturbance of kaan forests: relics of a community protected climax vegetation in the central Western Ghats. Trop Ecol 54(1):117-131

Haddaway NR, Woodcock P, Macura B, Collins A (2015) Making literature reviews more reliable through application of lessons from systematic reviews. Conserv Biol 29(6):1596-1605. https://doi.org/10. 1111/cobi. 12541

Hamer KC, Hill JK, Lace LA, Langan AM (1997) Ecological and biogeographical effects of forest disturbance on tropical butterflies of Sumba, Indonesia. J Biogeogr 24:67-75. https://doi.org/10.1111/j. 1365-2699.1997.tb00051.x

Holm S (1979) A simple sequentially rejective mul- tiple test procedure. Scand J Stat 6:65-70

IUCN WCPA (2019) Guidelines for recognising and reporting other effective areabased conservation measures. IUCN, Gland

Koricheva J, Gurevitch J, Mengersen K (2013) Handbook of meta-analysis in ecology and evolution. Princeton University Press, Princeton

Kotze TJVW, Gokhale DV (1980) A comparison of the pearson-X 2 and log-likelihood-ratio statistics for small samples by means of probability ordering. J Stat Comput Simul 12(1):1-13. https://doi.org/10. $1080 / 00949658008810422$

Kühnert K, Grass I, Waltert M (2019) Sacred groves hold distinct bird assemblages within an Afrotropical savanna. Glob Ecol Conserv 18:e00656. https://doi.org/10.1016/j.gecco.2019.e00656

Laurance WF, Carolina Useche D, Rendeiro J, Kalka M, Bradshaw CJA, Sloan SP, Laurance SG, Campbell M, Abernethy K, Alvarez P, Arroyo-Rodriguez V, Ashton P, Benítez-Malvido J, Blom A, Bobo KS, Cannon CH, Cao M, Carroll R, Chapman C, Coates R, Cords M, Danielsen F, de Dijn B, Dinerstein E, Donnelly MA, Edwards D, Edwards F, Farwig N, Fashing P, Forget P-M, Foster M, Gale G, Harris D, Harrison R, Hart J, Karpanty S, John Kress W, Krishnaswamy J, Logsdon W, Lovett J, Magnusson W, Maisels F, Marshall AR, Mcclearn D, Mudappa D, Nielsen MR, Pearson R, Pitman N, van der Ploeg J, Plumptre A, Poulsen J, Quesada M, Rainey H, Robinson D, Roetgers C, Rovero F, Scatena F, Schulze C, Sheil D, Struhsaker T, Terborgh J, Thomas D, Timm R, Nicolas Urbina-Cardona J, Vasudevan K, Joseph Wright 
S, Carlos Arias-G J, Arroyo L, Ashton M, Auzel P, Babaasa D, Babweteera F, Baker P, Banki O, Bass M, Bila-Isia I, Blake S, Brockelman W, Brokaw N, Brühl CA, Bunyavejchewin S, Chao J-T, Chave J, Chellam R, Clark CJ, Clavijo J, Congdon R, Corlett R, Dattaraja HS, Dave C, Davies G, de Mello Beisiegel B, de Nazaré Paes da Silva R, Di Fiore A, Diesmos A, Dirzo R, Doran-Sheehy D, Eaton M, Emmons L, Estrada A, Ewango C, Fedigan L, Feer F, Fruth B, Giacalone Willis J, Goodale U, Goodman S, Guix JC, Guthiga P, Haber W, Hamer K, Herbinger I, Hill J, Huang Z, Fang Sun I, Ickes K, Itoh A, Ivanauskas N, Jackes B, Janovec J, Janzen D, Jiangming M, Jin C, Jones T, Justiniano H, Kalko E, Kasangaki A, Killeen T, King H-B, Klop E, Knott C, Koné I, Kudavidanage E, da Silva L, Ribeiro J, Lattke J, Laval R, Lawton R, Leal M, Leighton M, Lentino M, Leonel C, Lindsell J, Ling-Ling L, Eduard Linsenmair K, Losos E, Lugo A, Lwanga J, Mack AL, Martins M, Scott Mcgraw W, Mcnab R, Montag L, Myers Thompson J, Nabe-Nielsen J, Nakagawa M, Nepal S, Norconk M, Novotny V, O'donnell S, Opiang M, Ouboter P, Parker K, Parthasarathy N, Pisciotta K, Prawiradilaga D, Pringle C, Rajathurai S, Reichard U, Reinartz G, Renton K, Reynolds G, Reynolds V, Riley E, Rödel M-O, Rothman J, Round P, Sakai S, Sanaiotti T, Savini T, Schaab G, Seidensticker J, Siaka A, Silman MR, Smith TB, de Almeida SS, Sodhi N, Stanford C, Stewart K, Stokes E, Stoner KE, Sukumar R, Surbeck M, Tobler M, Tscharntke T, Turkalo A, Umapathy G, van Weerd M, Vega Rivera J, Venkataraman M, Venn L, Verea C, Volkmer de Castilho C, Waltert M, Wang B, Watts D, Weber W, West P, Whitacre D, Whitney K, Wilkie D, Williams S, Wright DD, Wright P, Xiankai L, Yonzon P, Zamzani F (2012) Averting biodiversity collapse in tropical forest protected areas. Nature 489:290-294. https://doi.org/10.1038/nature11318

Liu X, McGarrity ME, Bai C, Ke Z, Li Y (2013) Ecological knowledge reduces religious release of invasive species. Ecosphere 4(2):21. https://doi.org/10.1890/ES12-00368.1

Locke H (2013) Nature needs half: a necessary and hopeful new agenda for protected areas. Parks 19(2):1322. https://doi.org/10.2305/IUCN.CH.2013.PARKS-19-2.HL.en

Marini Govigli V, Healey J, Wong JLG, Stara K, Tsiakiris R, Halley JM (2020) When nature meets the divine: effect of prohibition regimes on the structure and tree-species composition of sacred forests in Northern Greece. Web Ecol 20(2):53-86. https://doi.org/10.5194/we-20-53-2020

Mcdonald JH (2014) Handbook of biological statistics, 3rd edn. Sparky House Publishing, Baltimore

Mikusiński G, Possingham HP, Blicharska M (2013) Biodiversity priority areas and religions-a global analysis of spatial overlap. Oryx 48(1):17-22. https://doi.org/10.1017/S0030605312000993

Myers N, Mittermeier R, Mittermeier CG, da Fonseca GAB, Kent J (2000) Biodiversity hotspots for conservation priorities. Nature 403:853-858. https://doi.org/10.1038/35002501

Nilsson SG, Ericson L (1997) Conservation of plant and animal populations in theory and practice. In: Hansson L (ed) Ecological principles of nature conservation. Conservation ecology series: principles, practices and management. Springer, Boston, pp 71-112

Nopper J, Ranaivojaona A, Riemann JC, Rödel M-O, Ganzhorn JU (2017) One forest is not like another: the contribution of community-based natural resource management to reptile conservation in Madagascar. Trop Conserv Sci 10:1-9. https://doi.org/10.1177/1940082917693234

Olejnik S, Li J, Supattathum S, Hu CJ (1997) Multiple testing and statistical power with modified Bonferroni procedures. J Educ Behav Stat 22:389-406

Olson DM, Dinerstein E, Wikramanayake ED, Burgess ND, Powell GVN, Underwood EC, D’Amico JA, Itoua I, Strand HE, Morrison JC, Loucks CJ, Allnutt TF, Ricketts TH, Kura Y, Lamoreux JF, Wettengel WW, Hedao P, Kassem KR (2001) Terrestrial ecoregions of the world: a new map of life on earth. Bioscience 51(11):933-938

Ormsby A (2013) Analysis of local attitudes toward the sacred groves of Meghalaya and Karnataka, India. Conserv Soc 11(2):187-197. https://doi.org/10.4103/0972-4923.115722

Parker S (2012) Small reserves can successfully preserve rare plants despite management challenges. Nat Areas J 32(4):403-411. https://doi.org/10.3375/043.032.0409

Pebesma E (2018) Simple features for R: standardized support for spatial vector data. R J 10(1):439-446. https://doi.org/10.32614/RJ-2018-009

Pedersen TL (2020) patchwork: the composer of plots. R package version 1.0.1. https://CRAN.R-project. org/package $=$ patchwork

Pullin AS, Stewart GB (2006) Guidelines for systematic review in conservation and environmental management. Conserv Biol 20:1647-1656. https://doi.org/10.1111/j.1523-1739.2006.00485.x

R Core Team (2020) R: a language and environment for statistical computing. R foundation for statistical computing, Vienna, Austria. https://www.R-project.org/

Reynolds TW, Collins CD, Wassie A, Liang J, Briggs W, Lowman M, Shimekach Sisay T, Adamu E (2016) Sacred natural sites as mensurative fragmentation experiments in long-inhabitated multifunctional landscapes. Ecography 40:144-157. https://doi.org/10.1111/ecog.02950

Rutte C (2011) The sacred commons: conflicts and solutions of resource management in sacred natural sites. Biol Conserv 144(10):2387-2394. https://doi.org/10.1016/j.biocon.2011.06.017 
Salick J, Amend A, Anderson D, Hoffmeister K, Gunn B, Zhendong F (2007) Tibetan sacred sites conserve old growth trees and cover in the eastern Himalayas. Biodivers Conserv 16:693-706. https://doi.org/ 10.1007/s10531-005-4381-5

Shepheard-Walwyn E, Bhagwat S (2018a) Maintaining standing stones benefits biodiversity in lowland heathland. Oryx 52(2):240-249. https://doi.org/10.1017/S0030605317001442

South A (2017) rnaturalearth: world map data from natural earth. R package version 0.1.0. https://CRAN.Rproject.org/package $=$ rnaturalearth

Stara K, Tsiakiris R, Wong JLG (2015) The trees of the sacred natural sites of Zagori, NW Greeze. Lands Res 40(7):884-904. https://doi.org/10.1080/01426397.2014

Stara K, Tsiakiris R, Nitsiakos V, Halley JM (2016) Religion and management of the commons. The sacred forests of Epirus. In: Agnoletti M, Emanueli F (eds) Biocultural diversity in europe environmental history, vol 5. Springer, Cham, pp 283-302. https://doi.org/10.1007/978-3-319-26315-1_15

Tiwari BK, Tynsong H, Lynser MB (2010a) Forest management practices of the tribal people of Meghalaya, north-east India. J Trop for Sci 22(3):329-342

Vetter D, Rücker G, Storch I (2013) Meta-analysis: a need for well-defined usage in ecology and conservation biology. Ecosphere 4(6):74. https://doi.org/10.1890/ES13-00062.1

Watson J, Dudley N, Segan D, Hockings M (2014) The performance and potential of protected areas. Nature 515:67-73. https://doi.org/10.1038/nature13947

Wickham H (2016) ggplot2: elegant graphics for data analysis. Springer, New York. https://ggplot2.tidyv erse.org

Wilson EO (2016) Half-earth: our planet's fight for life. W.W. \& Norton Company, New York. https://doi. org/10.1149/1.3635578

\section{Data sources}

Ambinakudige S, Sathish BN (2009) Comparing tree diversity and composition in coffee farms and sacred forests in the western ghats of India. Biodivers Conserv 18:987-1000. https://doi.org/10.1007/ s10531-008-9502-5

Avtzis DN, Stara K, Sgardeli V, Betsis A, Diamandis S, Healey JR, Kapsalis E, Kati V, Korakis G, Marini Govigli V, Monokrousos N, Muggia L, Nitsiakos V, Papadatou E, Papaioannou H, Rohrer A, Tsiakiris R, van Houtan KS, Vokou D, Wong JLG, Halley JM (2018b) Quantifying the conservation value of sacred natural sites. Biol Conserv 222:95-103. https://doi.org/10.1016/j.biocon.2018.03.035

Bhagwat SA, Kushalappa CG, Williams PH, Brown ND (2005b) A landscape approach to biodiversity conservation of sacred groves in the Western Ghats of India. Conserv Biol 18:1853-1862. https://doi.org/ 10.1111/j.1523-1739.2005.00248.x

Bhagwat SA, Kushalappa CG, Williams PH, Brown ND (2005c) The role of informal protected areas in maintaining biodiversity in the Western Ghats of India. Ecol Soc 10(1):8. https://doi.org/10.5751/ ES-01285-100108

Boadi S, Nsor CA, Yakubu DH, Acquah E, Antobre OO (2017) Conventional and indigenous biodiversity conservation approach: a comparative study of Jachie sacred grove and Nkrabea forest reserve. Int $\mathrm{J}$ for Res. https://doi.org/10.1155/2017/1721024

Boraiah KT, Vasudeva R, Bhagwat SA, Kushalappa CG (2003) Do informally managed sacred groves have higher richness and regeneration of medicinal plants than state-managed reserve forests? Curr Sci 84(6):804-808

Bossart JL, Opuni-Frimpong E, Kuudaar S, Nkrumah E (2006b) Richness, abundance, and complementarity of fruit-feeding butterfly species in relict sacred forests and forest reserves of Ghana. Biodivers Conserv 15:333-359. https://doi.org/10.1007/s10531-005-2574-6

Brandt JS, Wood EM, Pidgeon AM, Han LX, Fang Z, Radeloff VC (2013) Sacred forests are keystone structure for forest bird conservation in southwest China's Hymalayan Mountains. Biol Conserv 166:34-42. https://doi.org/10.1016/j.biocon.2013.06.014

Brown N, Bhagwat SA, Watkinson S (2006b) Macrofungal diversity in fragmented and disturbed forests of the Western Ghats of India. J Appl Ecol 43:11-17. https://doi.org/10.1111/j.1365-2664.2005.01107.x

Campbell MO (2004) Traditional forest protection and woodlots in the coastal savannah of Ghana. Environ Conserv 31(3):225-232. https://doi.org/10.1017/S0376892904001389

Campbell MO (2005) Sacred groves for forest conservation in Ghana's coastal savannas: assessing ecological and social dimensions. Singap J Trop Geogr 26(2):151-169. https://doi.org/10.1111/j.0129-7619. 2005.00211.x 
Frascaroli F, Bhagwat S, Guarino R, Chiarucci A, Schmid B (2016b) Shrines in Central Italy conserve plant diversity and large trees. Ambio 45:468-479. https://doi.org/10.1007/s13280-015-0738-5

Fraser JA, Diabaté M, Narmah W, Beavogui P, Guilavogui K, de Foresta H, Junqueira AB (2016) Cultural valuation and biodiversity conservation in the Upper Guinea forest, West Africa. Ecol Soc 21(3):36. https://doi.org/10.5751/ES-08738-210336

Gunaga S, Rajeshwari N, Vasudeva R (2013) Tree diversity and disturbance of kaan forests: relics of a community protected climax vegetation in the central Western Ghats. Trop Ecol 54(1):117-131

Karun NC, Sridhar KR (2016) Spatial and temporal diversity of macrofungi in the western ghat forests of India. Appl Ecol Environ Res 14(2):1-21. https://doi.org/10.15666/aeer/1402_001021

Kühnert K, Grass I, Waltert M (2019) Sacred groves hold distinct bird assemblages within an Afrotropical savanna. Glob Ecol Conserv 18:e0656. https://doi.org/10.1016/j.gecco.2019.e00656

Lotemplio S, Reynolds TW, Wassie Eshete A, Abrahams M, Bruesewitz D, Wall JA (2016) Ethiopian Orthodox church forests provide regulating and habitat services: evidence from stream sediment and aquatic insect analyses. Afr J Ecol 55:247-251

Maheswarappa V, Vasudeva R (2018) Structural and floristic diversity of different landscape in Western Ghats of Kodagu, Karnataka, India. Indian J Ecol 45(3):462-469

Mgumia FH, Oba G (2003) Potential role of sacred groves in biodiversity conservation in Tanzania. Environ Conserv 30(3):259-265. https://doi.org/10.1017/S0376892903000250

Nopper J, Ranaivojaona A, Riemann JC, Rödel M-O, Ganzhorn JU (2017) One forest is not like another: the contribution of community-based natural resource management to reptile conservation in Madagascar. Trop Conserv Sci 10:1-9. https://doi.org/10.1177/1940082917693234

Onyekwelu JC, Olusola JA (2014) Role of sacred grove in in-situ biodiversity conservation in rainforest zone of south-western Nigeria. J Trop for Sci 26(1):5-15

Page NV, Qureshi Q, Rawat GS, Kushalappa CG (2010) Plant diversity in sacred forest fragments of Western Ghats: a comparative study of four life forms. Plant Ecol 206(2):237-250. https://doi.org/10.1007/ s11258-009-9638-8

Rao BRP, Babu MVS, Reddy MS, Reddy AM, Rao VS, Sunitha S, Ganeshaiah KN (2011) Sacred groves in southern eastern ghats, India: are they better managed than forest reserves? Trop Ecol 52(1):79-90

Salick J, Amend A, Anderson D, Hoffmeister K, Gunn B, Zhendong F (2007) Tibetan sacred sites conserve old growth trees and cover in the eastern Himalayas. Biodivers Conserv 16:693-706. https://doi.org/ 10.1007/s 10531-005-4381-5

Shepheard-Walwyn E, Bhagwat SA (2018b) Maintaining standing stones benefits biodiversity in lowland heathland. Fauna Flora Int 52(2):240-249. https://doi.org/10.1017/S0030605317001442

Tankou CM, de Snoo GR, de Iongh HH, Persoon G (2013) Variation in plant biodiversity across sacred groves and fallows in Western Highlands of Cameroon. Afr J Ecol 52(1):10-19

Tiwari BK, Tynsong H, Lynser MB (2010b) Forest management practices of the tribal people of meghalaya, north-east India. J Trop for Sci 22(3):329-342

Wild R, Mcleod C (2008) Sacred natural sites Guidelines for protected area managers. IUCN, Gland, Switzerland

Publisher's Note Springer Nature remains neutral with regard to jurisdictional claims in published maps and institutional affiliations.

\section{Authors and Affiliations}

\section{Piero Zannini ${ }^{1}(\mathbb{D}) \cdot$ Fabrizio Frascaroli $^{1,2} \cdot$ Juri Nascimbene $^{1} \mathbb{D} \cdot$ Angela Persico $^{1}$. John Maxwell Halley ${ }^{3}$. Kalliopi Stara ${ }^{3}$ (D) Gabriele Midolo ${ }^{4}$ (D) Alessandro Chiarucci ${ }^{1}$ (D)}

1 BIOME Lab, Department of Biological, Geological and Environmental Sciences, Alma Mater Studiorum - University of Bologna, Via Irnerio 42, 40126 Bologna, Italy

2 Lòm Research, Via Re Manfredi 38, 03030 Rocca d'Arce, FR, Italy

3 Department of Biological Applications and Technology, University of Ioannina, 45110 Ioannina, Greece

4 Faculty of Science and Technology, Free University of Bozen-Bolzano, Bolzano, Italy 